\title{
Hypothyroidism and In Vitro Fertilization
}

\author{
Adegbenga B Ademolu* \\ Medicine department, Lagos State University Teaching Hospital, Nigeria \\ *Corresponding author: Adegbenga B Ademolu, Medicine department, Lagos State University Teaching Hospital, Ikeja lagos, \\ Nigeria.
}

To Cite This Article: Adegbenga B Ademolu. Hypothyroidism and In Vitro Fertilization. Am J Biomed Sci \& Res. 2019 - 2(4). AJBSR.MS.ID.000592. DOI: $10.34297 / A J B S R .2019 .02 .000592$

Received: April 13, 2019 | Published: April 17, 2019

\section{Editorial}

Technological advancement in various form is one of the innovations that has revolutionarized medical practice in the $21 \mathrm{st}$ century compared to the early days of medical practice prior to the existence of Hippocrates.

In vitro fertilization which has helped to solve the problem of infertility in some couple and individuals is one of such technological advancement innovations. In vitro fertilization is complex, expensive, invasive and time consuming, It involves harvesting ova (human female egg) and sperm from the male partner (or donor) and fertilizing (a process of bringing the ova in contact with the sperm so that the two can fuse to form a zygote (that is the embryo which over time develop into fetus which is born on maturity as a baby) outside the female reproductive system and outside the female body. The embryo is later implanted back in the female uterus (or a gestational carrier - a woman who has an embryo implanted in her uterus) for growth into fetus and a matured baby ready to be born.

During the period outside the body, the ova, sperm and resultant embryo are temporarily free from the physiologic condition of the internal milieu including being free from the hormones that affects embryo and fetal growth indirectly by modulating maternal basal metabolic rate especially triiodothyronine and tetraiodothyronine.

However, it is well documented in literature that there are cases of failed in vitro fertilization procedure in some cases occurring more than once in the same individual. Since personal or corporate resources involved in in vitro fertilization is substantial, then scientifically proven effort at finding the cause of infertility and establishing indication for in vitro fertilization should be well established and the effects such causes will have on the embryo post transfer into the uterus should be well envisaged with aim of preventing fetal loss.
Hypothyroidism is a metabolic cause of infertility that can result in in vitro fertilization failure if not diagnosed and controlled appropriately throughout pregnancy. Hypothyroidism as an endocrinopathy is one that can result not only in fetal loss after an embro is implanted in the uterus following fertilization in vitro but can cause repeated fetal loss post procedure if not diagnosed. The defi ciency of triiodothyronine and tetraiodothyronine slows maternal basal metabolic rate and in return compromise nutrients supply to the fetus through placenta exchange.

I recently managed a post-menopausal woman who had had at least two failed in vitro fertilization during her reproductive age meanwhile she is Hypothyroid and this was undiagnosed until l reviewed her! Her previous in vitro fertilization failure was said to be due to an unknown cause! Meanwhile her hypothyroidism had been long standing as suggested by her history including hailing from goiter endermic region, being naturally a slow or sluggish individual and having recurrent anterior neck swelling for years which she overlooked as it is usually small sized and usually regressed. The diagnosis of hypothyroidism was confirmed by an assay of her thyroid function test when she presented with features in keeping with multiple myeloma with cord compression. An early diagnosis of her hypothyroidism could have saved her the headache of passing through repeated failed in vitro fertilization.

Hence l want to emphasize the role of metabolic causes like hypothyroidism in the aetiology of infertility especially in patients with infertility needing in vitro fertilization with challenges of failed procedure that once diagnosed is achieved from high index of suspicion and laboratory workup,good contol of thyroid hormone should be achieved before and following implant of embryo in the uterus throughout pregnancy in order to avoid fetal wastage in a procedure that is mentally tasking to both patient and doctors and medical team so as to reduce the failure rate of in vitro fertilization. 